\title{
Pore-scale observation of surfactant flooding for weekly water-wet porous media: the effect of gas injection to improve oil recovery
}

\author{
T. Suekane ${ }^{1} \&$ R. Tezuka ${ }^{2}$ \\ ${ }^{1}$ Department of Energy Sciences, Tokyo Institute of Technology, Japan \\ ${ }^{2}$ Department of Mechanical Engineering, \\ University of Tokushima, Japan
}

\begin{abstract}
Surfactant flooding is one of the effective methods to produce trapped oil after water flooding. Surfactant is injected into reservoirs to reduce the interfacial tension between the trapped oil and water. However, at the pore scale, the mechanism of how the injected surfactant reaches the interface through the stagnant water adjacent to the interface has not been completely explained yet. This research provides new insights into the transport phenomena of multiphase flow in porous media using two-dimensional micro-model curved on a quartz glass plate. When the surfactant is injected after water flooding, stagnant water which extends a few pores from the interface, hampers the arrival of the surfactant. It is found that gas injection before the surfactant flooding increases the oil recovery with reducing amount of injected surfactant. Injected gas flows through the water and there is no direct effect on oil production. However, during the successive surfactant flooding, the gas bubbles are trapped in porous media which changes the flow of surfactant to reach the interface of the trapped oil.
\end{abstract}

Keywords: surfactant flooding, enhanced oil recovery, porous plate, gas injection, oil trapping

\section{Introduction}

Primary recovery of oil utilizes the pressure of the reservoir to flow naturally to the bottom of the production well, but production is limited less than $15 \%$ of 
original oil in place because of sudden drop in pressure. Water flooding is commonly used to recover the reservoir pressure and to keep the production of oil. During the primary and secondary recovery some fraction of oil is swept by water, but the other fraction is trapped in reservoir rock due to the capillary pressure. On average, about $60 \%$ of original oil in place remains behind in the reservoir. Surfactant flooding, which can enhance oil recovery, re-mobilizes trapped oil by reducing the interfacial tension between oil and water. Amount of surfactant injected into the reservoir should be reduced as much as possible to improve the economic feasibility of the surfactant flooding. Adsorption of the surfactant on the solid matrix of porous rock shortens the sweeping distance from the injection well [1]. In present paper, the authors focused on the flow around the trapped oil blobs from the microscopic point of view. In the trapped oil blobs, the velocity averaged over the blob volume should be zero. The continuity of fluid flow claims that water around the oil blobs should be rest as a stagnant film surrounding the oil blob. The injected surfactant is transported by convection to the outer edge of the stagnant film, but it might be transported by molecular diffusion across the film to reach the interface between oil and water. In present paper we used the porous plate, which has two-dimensional pore networks etched on the glass plate to observe experimentally the stagnant region surrounding the trapped oil blobs. We propose gas injection prior to surfactant injection in order to reduce the amount of injection volume of surfactant by disturbing the flow paths of water phase.

\section{Experimental facilities and procedures}

\subsection{Experimental facilities}

Etched glass micro-models have been used by several researchers to study fluid flows in porous media [2-5], because two-dimensional configuration allows us to easily observe the details of the flow phenomena at pore-scale. Figure 1 shows the glass micro-model we used for the experiments. A pore network structure was carved on a quartz glass plate with a depth of $90 \mu \mathrm{m}$ by utilizing a special abrasive blasting technique. After blasting, an upper quartz glass plate was placed over the first plate covering the carved pore network structure. Then, these two plates were attached by an optical contact technique. Inlet and outlet holes were drilled at each end through the upper plate to serve as inlet and outlet ports.

The pore structure has 1502 circular pores and 2128 throats with the pore to throat coordination number of 4 . Triangle cavities with the inlet and outlet holes on a corner are attached on both side of the pore network pattern, which has a width of $34.2 \mathrm{~mm}$ and a length of $68.4 \mathrm{~mm}$. Details about the pore diameter and throat width are summarized in Table 1 . The pore structure was designed with reference to Vizika and Payatakes [6].

We used $n$-dodecane dyed with Sudan Red with $0.12 \mathrm{wt} \%$ as a non-wetting phase and distilled water dyed with methylene blue with $0.15 \mathrm{wt} \%$ as a wetting phase. As surfactant fluid, mixture of water and detergent (Family Fresh, KAO) 
which contains $18 \mathrm{wt} \%$ of fatty alcohol-based surfactant as the principal component.

\subsection{Experimental procedure}

Before the experiments the models are cleaned by injecting like distilled water, acid, and alcohol and then they are dried. First, the micro-model is filled with a non-wetting fluid by using the vacuum chamber. Then the micro-model is placed horizontally under a still camera (EOS-50D with a $100 \mathrm{~mm}$ macro lens, Canon). A high-accuracy, low-rate pump (KDS-210, kdScientific) was used to control at constant injection flow rate. First, a few pore volumes of distilled water was injected until the non-wetting phase became immobile. Second, in some cases a few pore volumes of air was injected until the interface in the micro-model became immobile. Finally, the surfactant was injected into the micro-model. The injection flow rate is common for all fluids at $0.012 \mathrm{ml} / \mathrm{min}$. The capillary number is $\mathrm{Ca}=\mu_{w} Q_{w} / A \sigma=2.07 \times 10^{-6}$, where $\mu_{w}=1.002 \mathrm{mPa} \cdot \mathrm{s}$ is the viscosity of water, $Q_{w}$ is the flow rate, $A$ is the total cross-sectional area of the network entrance, namely $A=$ (width of the entrance) $\times$ (depth of the carved region), $\sigma=31.5 \mathrm{mN} / \mathrm{m}$ is the interfacial tension between $n$-dodecane and water.

Table 1: Geometric characteristics of the porous medium micro-model.

\begin{tabular}{|c|c|c|c|}
\hline $\begin{array}{l}{[1]} \\
{[2]}\end{array}$ & $\begin{array}{l}\text { Pore diameter, } \\
\mu \mathrm{m}\end{array}$ & $\begin{array}{l}\text { [3] Throat width, } \\
\text { [4] } \mu \mathrm{m}\end{array}$ & $\begin{array}{l}\text { [5] Frequency of } \\
\text { appearance, \% }\end{array}$ \\
\hline & [6] 450 & [7] 90 & [8] 11.5 \\
\hline & [9] 585 & [10] 117 & {$[11] 23.0$} \\
\hline & {$[12] 720$} & [13] 144 & {$[14] 31.0$} \\
\hline & {$[15] 855$} & [16] 171 & {$[17] 23.0$} \\
\hline & [18]900 & [19] 198 & {$[20] 11.5$} \\
\hline
\end{tabular}

Table 2: $\quad$ Properties of fluids.

\begin{tabular}{|c|c|c|c|}
\hline [21] & {$[22]$} & $\begin{array}{c}\text { [23] density, } \\
\mathrm{g} \mathrm{cm}^{2}\end{array}$ & $\begin{array}{c}\text { [24] viscosity, } \\
\text { mPas }\end{array}$ \\
\hline [25] water & [26] distilled water & [27] 1.055 & [28]0.890 \\
\hline [29] oil & $\begin{array}{l}\text { [30] } n \text {-dodecane doped } \\
\text { with Sudan Red } \\
0.12 \text { wt } \%\end{array}$ & {$[31] 0.781$} & [32] 1.34 \\
\hline [33] gas & [34] nitrogen & {$[35] 1.184 \times 10^{-4}$} & [36] 0.0182 \\
\hline [37] surfactant & $\begin{array}{l}\text { [38] distilled water }+ \\
\text { detergent } 0.15 \\
\text { wt } \%\end{array}$ & [39]- & [40]- \\
\hline
\end{tabular}




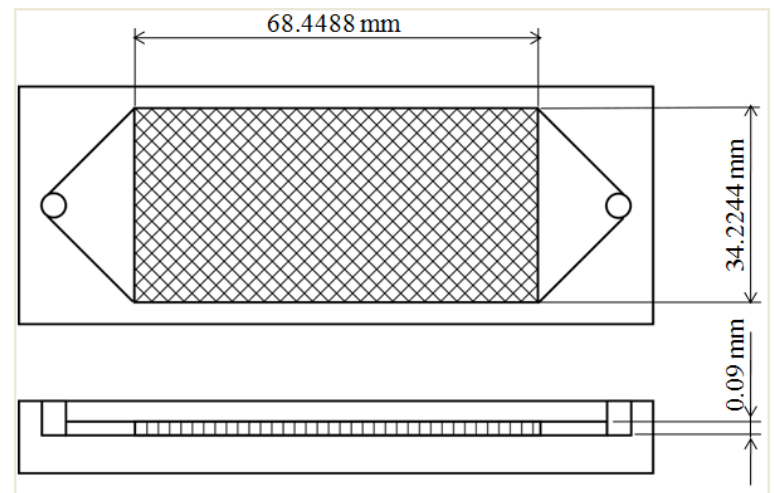

(a)

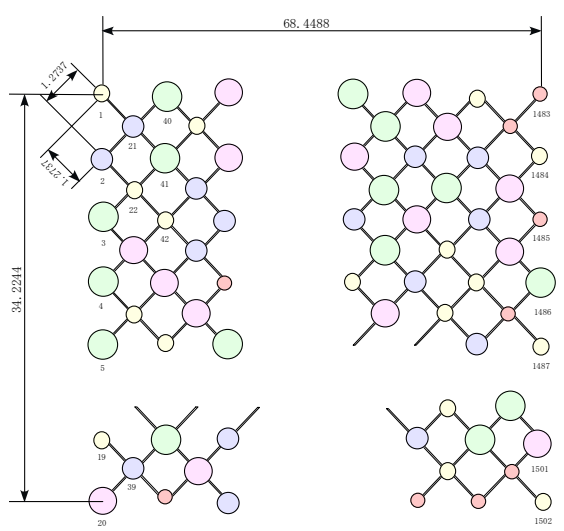

(b)

Figure 1: $\quad$ Porous plate.

\section{Experimental results}

\subsection{Surfactant flooding without gas injection}

Figures 2 and 3 show the snapshot of fluid distribution on the porous plate without gas injection. In Fig. 2, $S_{o}$ denotes the oil saturation. Water was injected into the porous plate almost saturated with oil. Water imbibes into each throat at different speed due to capillary pressure depending on the throat diameter. Because displacing water is less viscous than the displaced oil, viscous fingering will make the interface unstable. As a result, some oil-filled pores are by-passed by imbibing water and are disconnected from the continuum oil to the exit port. The isolated oil blobs are trapped in the porous plate due to capillarity. At the steady state, the residual oil saturation, $S_{o}{ }^{*}$, was $26.8 \%$ (Fig. 2(b)). The observation of the interface by a microscope gives the contact angle of water to the glass surface is in the range between $67^{\circ}$ and $77^{\circ}$. Then injecting water was 


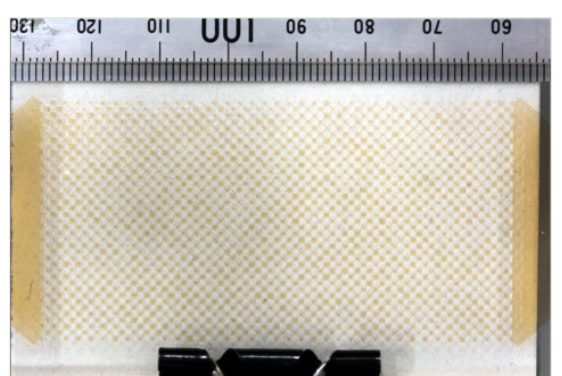

(a) Initial

$S_{o}=100 \%$

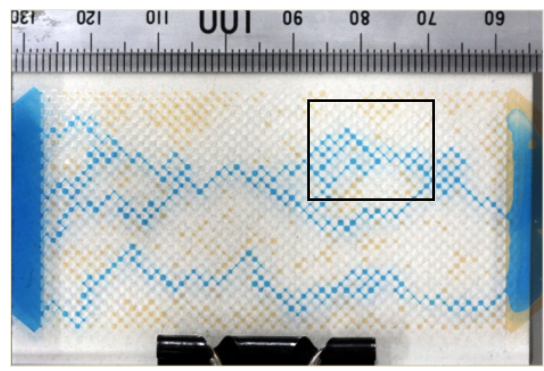

(c) Water injection (blue)

$S_{o}=28.4 \%$

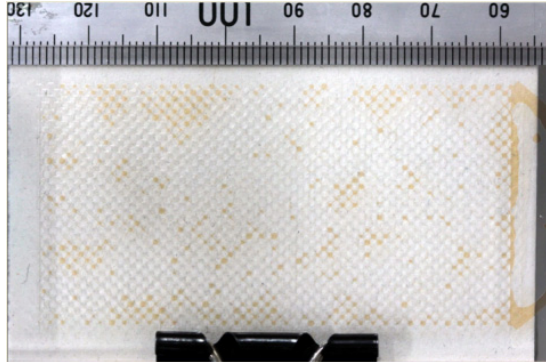

(b) Water injection (clear)

$S_{o}=28.6 \%$

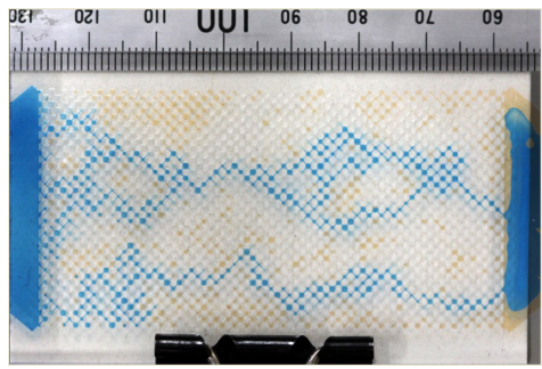

(d) Surfactant injection part 1 (2 1. PV)

$S_{o}=28.4 \%$

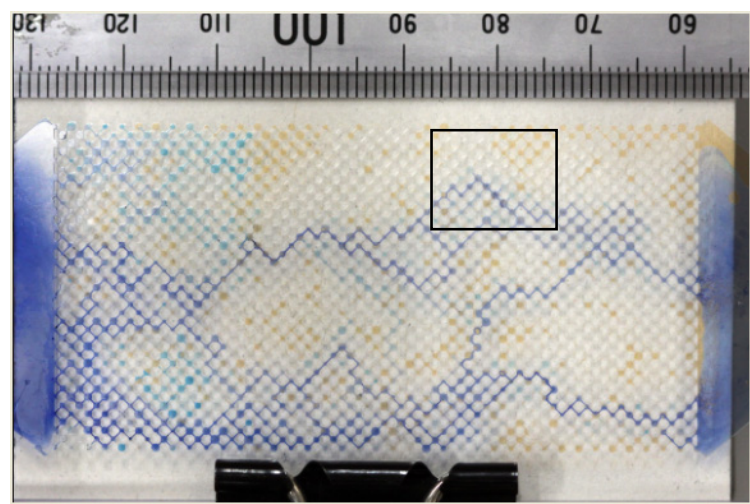

(e) Surfactant injection part 2 (4.7 PV)

$$
S_{o}=18.24 \%
$$

Figure 2: Surfactant flooding without gas injection: (a) the porous plate is almost saturated with oil, (b) as not dyed water was injected from the left side, oil trapped in the porous plate by capillarity, (c) successive dyed water injection, and (d) dyed surfactant injection. 
switched to dyed water to visualize the flow paths. A few water flowing paths can be obviously displayed in Fig. 2(c). The pores filled with transparent water denote stagnant regions surrounding the trapped oil blobs. There exit some oil blobs of which all adjacent pores are filled with stagnant water. On the other hand, for some oil blobs water in several adjacent pores is flowing, but stagnant throats separate a direct contact between flowing water and trapped oil as shown in Fig. 3a. Then, surfactant was injected into the plate. The flow paths of surfactant remain same with those of water. Therefore, the injected surfactant cannot reach the interface of trapped oil blobs by convection. The injection of surfactant of one or two pore volumes does not contribute to the re-mobilization of oil blobs. After the transfer of surfactant by molecular diffusion across the stagnant layers, the trapped oil tends to be produced.

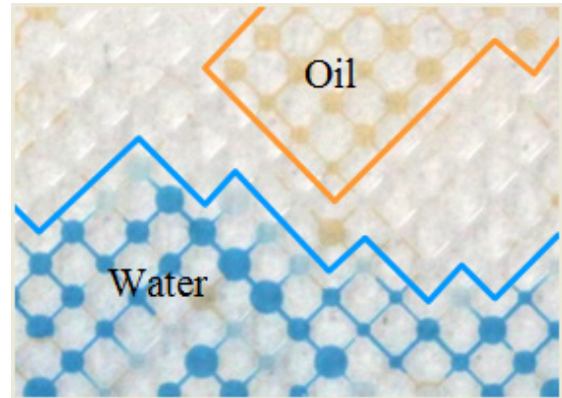

(a) Water injection

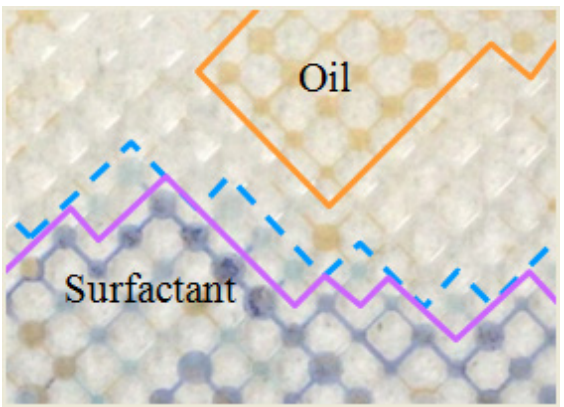

(b) Surfactant injection

Figure 3: Close-up views of the square regions in Figures 2(c) and (e) of surfactant flooding without gas injection.

\subsection{Surfactant flooding with gas injection}

In order to break the water flowing paths in the porous plate with trapped oil blobs, nitrogen was injected before surfactant flooding. First, the porous plate was almost $100 \%$ saturated with oil (Fig. 4(a)), then dyed water was injected into the plate (Fig 4(b)). Next, gas was injected. Among the three phase of oil, water, and gas, gas is less viscous and non-wetting to glass. When the gas pressure exceeds the capillary entrance pressure, gas pushes out water filling throat. Gas enters the pore network from the single point and displaces the surrounding water with the lowest entrance pressure. As a result, gas distribution shows the complicated fingering pattern as shown in Fig. 4(c). For the same throat diameter, the entrance pressure for oil is lower than that for water, because of wettability. Six displacement mechanisms can occur when the three phases are present in the same pore space [7-12]. Øren and Pinczewski [7] observed double drainage, where gas displaces oil that displaces water. In present experiments, however, gas almost only displaces the pores filled with water. Gas, which is immiscible to water, tends to flow along the water flow paths. This fact denotes that the gas migration is affected by not only the entrance pressure but also the trapped oil blobs. The pressure required to displace water is lower than that 


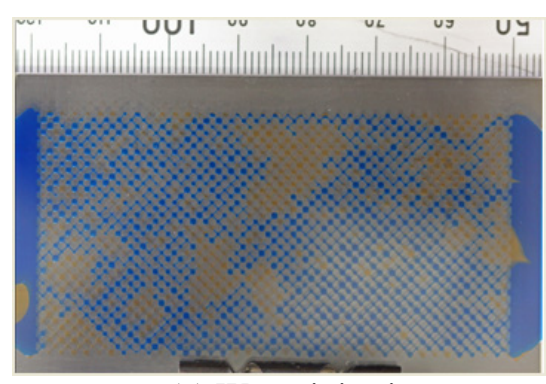

(a) Water injection

$S_{o}=28.9 \%$

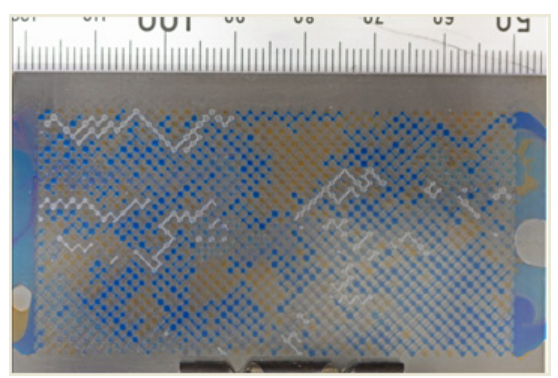

(c) Surfactant injection (0.8 PV)

$$
S_{o}=23.6 \%, S_{g}=10.8 \%
$$

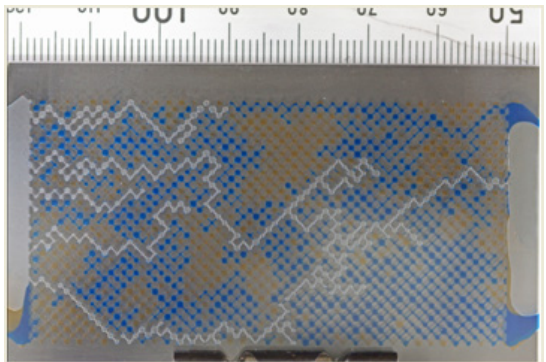

(b) Gas injection

$$
S_{o}=28.7 \%, S_{g}=20.4 \%
$$

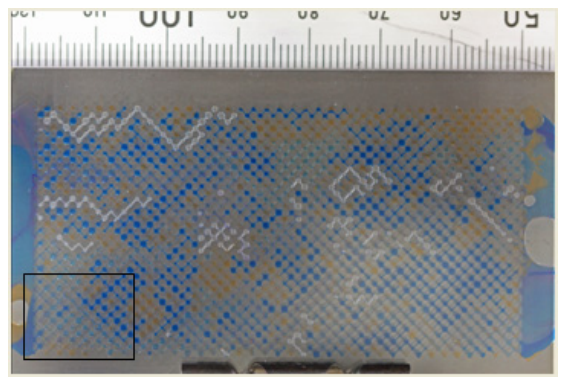

(d) Surfactant injection (1.2 PV)

$$
S_{o}=19.9 \%, S_{g}=10.6 \%
$$

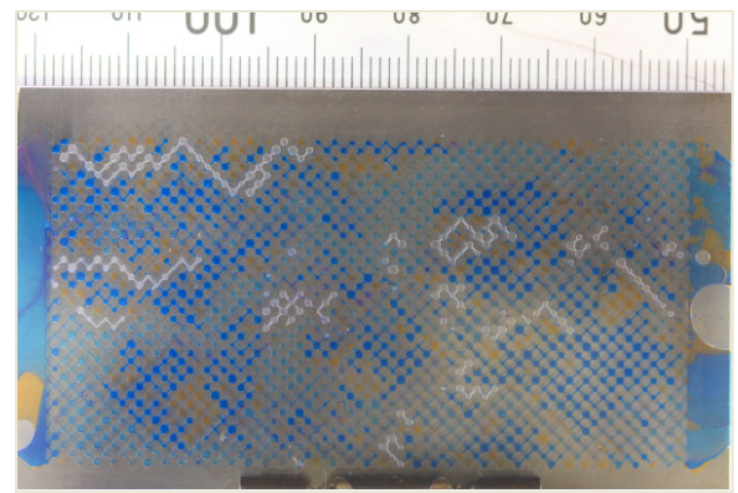

(e) Surfactant injection part 3 (1.4 PV)

$$
S_{o}=12.2 \%, S_{g}=10.4 \%
$$

Figure 4: Surfactant flooding with gas injection: (a) residual oil trapped in porous plate after water flooding dyed with blue, (b) injected gas flows through the pores and throats filled with water, (c, d, e) as the amount of surfactant, which is dyed with light, is injected into the porous plate, oil production proceeds. 
required to re-mobilize trapped oil. Therefore, gas injection itself does not contribute directly to enhanced oil production. Finally, surfactant was injected into the plate. Pre-injected gas is trapped in the porous plate by capillarity. These trapped gas bubbles plug the water flowing paths and impede the surfactant flow along the paths. Eventually, the surfactant changes the flowing paths and reaches the interface of the oil blobs.

Figure 5 shows the observed effect of gas injection on the following surfactant flooding. In the case of Fig. 5(a), the injected gas displaces the water adjacent to the oil blob. At the following surfactant flooding, surfactant imbibes into the pores filled with gas. During this imbibition process, surfactant attaches with the interface of the blob, which is produced after that. In the case of Fig. 5(b), the surfactant imbibes along the pores filled with gas, but when the front gas is trapped it changes flow direction to avoid trapped gas. Consequently, surfactant breaks into the oil blob.
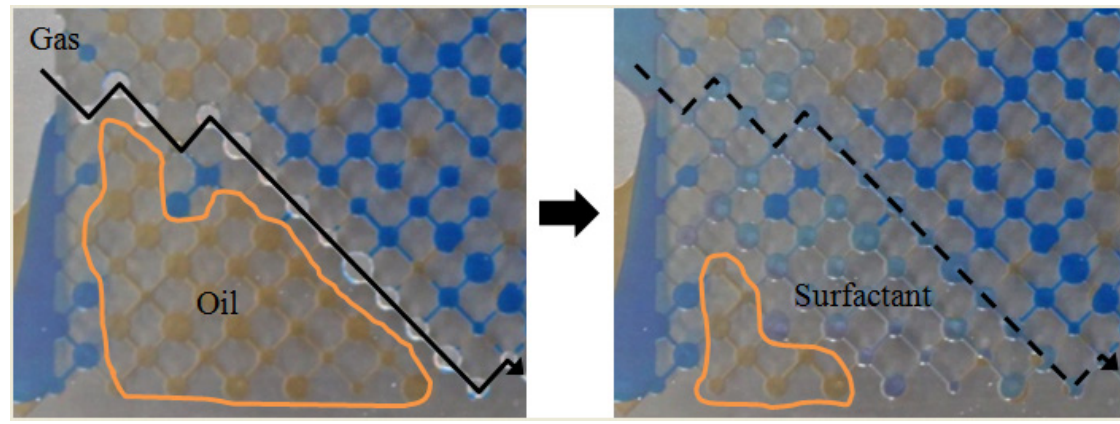

(a)
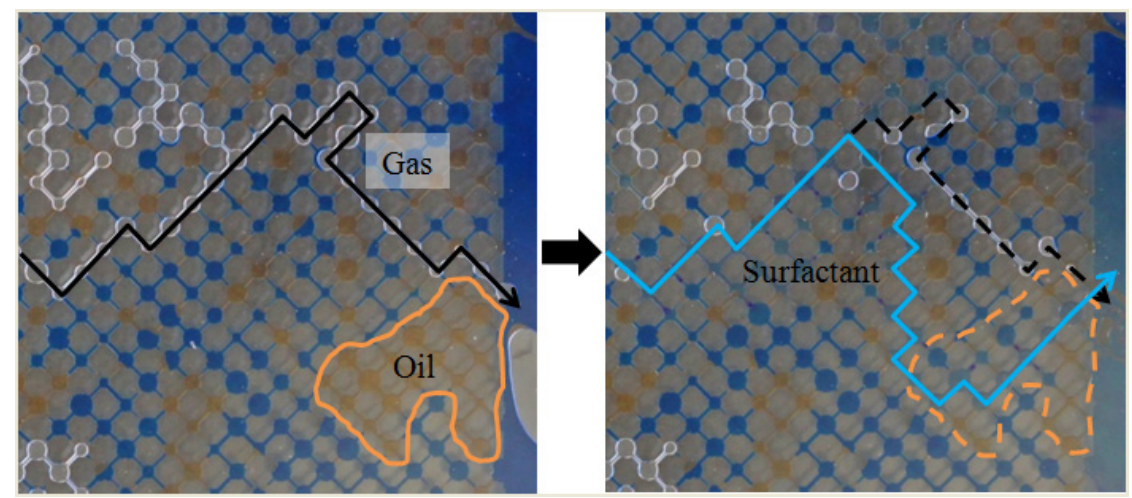

(b)

Figure 5: Effect of gas injection on following surfactant flooding: (a) surfactant imbibes in along gas filled pores with complicated fingering pattern; (b) trapped gas impedes the surfactant flow. 
Figure 6 shows trapped gas bubbles after surfactant injection. The surfactant flows through the corners of the pores filled with gas. In the three pores denoted by circles in the left bottom figure, the surfactant builds up at the corner of the pore. In the middle top pore in right bottom figure, the surfactant lefts the pore filled with gas and flows through the pores filled with water under a miscible condition. In the right throat in the right bottom figure, gas was snapped-off by surfactant. Surfactant imbibes into the corners by capillary pressure and spreads faster along the pores and throats filled with gas. This fact suggests that the surfactant could reach far away from the injection surface even for low amount of volume of injection.
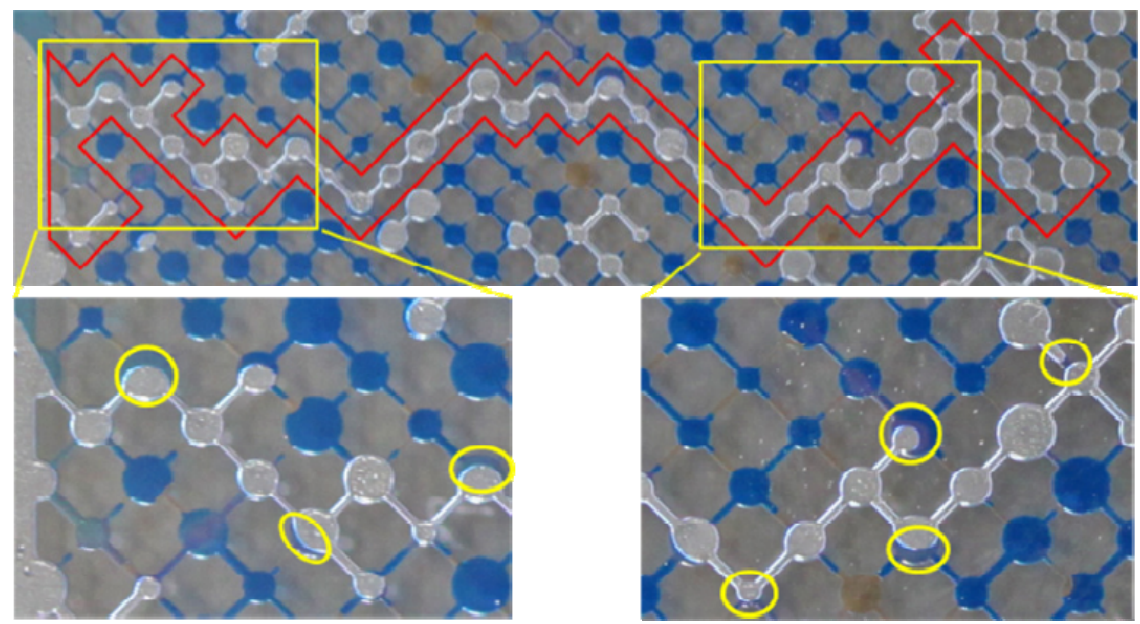

Figure 6: Imbibition of surfactant along the corners of pores and throats filled with gas. Bottom two figures are close up views of the top picture.

\section{Discussions}

We define the oil recovery by $1-S_{o} / S_{o}{ }^{*}$ which is the fraction of recovered oil to the trapped oil after primary water injection. Figure 7 shows the effect of gas injection on the oil recovery. If surfactant flooding follows water flooding without gas injection, the oil recovery is about $20 \%$ even after more than three pore volumes of surfactant is injected. If the gas is injected in prior to the surfactant injection, oil production is initiated at one pore volume injection of surfactant and increases up to $60 \%$ with surfactant injection.

\section{Conclusions}

We used the porous plate which has two-dimensional pore networks etched on the glass plate to observe experimentally the stagnant region surrounding the trapped oil blobs. Gas injection prior to surfactant injection is proposed in order 


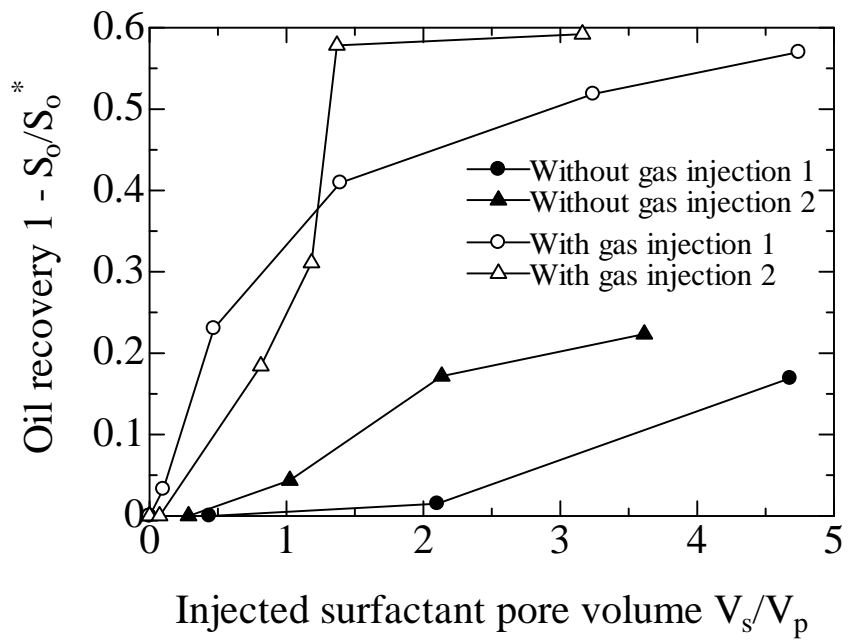

Figure 7: Relationship between the oil recovery and the injected pore volumes of surfactant, where $V_{s}$ denotes the volume of injected surfactant and $V_{p}$ is the pore volume.

to reduce the amount of injection volume of surfactant by disturbing the flow paths of water phase. When the surfactant is injected after water flooding, stagnant water, which extends a few pores from the interface, hampers the arrival of surfactant. It is found that gas injection before the surfactant flooding increases the oil recovery with reducing amount of injected surfactant. Injected gas flows through the water and there is no direct effect on oil production. But during the successive surfactant flooding, the gas bubbles are trapped in porous media, which changes the flow of surfactant to reach the interface of the trapped oil.

\section{References}

[1] Gogoi, S.B., Adsorption-desorption of surfactant for enhanced oil recovery, Transport in Porous Media, 90, 589-604, 2011.

[2] Meybodi, H.E., Kharrat, R., Wang, X., Study of microscopic and macroscopic displacement behaviors of polymer solution in water-wet and oil-wet media, Transport in Porous Media, 89, 97-120, 2011.

[3] Farzaneh, S.A., Dehghan, A.A., Kharrat, R., Ghazanfari, M.H., An experimental investigation of fracture physical properties on heavy oil displacement efficiency during solvent flooding, Energy Sources A, 33, 1993-2004, 2011. 
[4] Jamaloei, B.Y., Kharrat, R., Analysis of microscopic displacement mechanisms of dilute surfactant flooding in oil-wet and water-wet porous media, Transport in Porous Media, 81, 1-19, 2010.

[5] Dehghan, A.A., Farzaneh, S.A., Kharrat, R., Ghazanfari, M.H., Rashtchian, D., Pore-level investigation of heavy oil recovery during water alternating solvent injection process, Transport in Porous Media, 83, 653-666, 2010.

[6] Vizika, O, Payatakes, A.C., Parametric experimental study of forced imbibition in porous media, PCH Physico Chemical Hydrodynamics, 11, 187-204, 1989.

[7] Øren, P.E., Pinczewski, W.V., Fluid distribution and pore-scale displacement mechanisms in drainage dominated three-phase flow, Transport in Porous Media, 20, 105-133, 1995.

[8] Pereira, G.G., Pinczewski, W.V., Chan, D.Y.C., Paterson, L., Øren, P.E., Pore-scale network model for drainage-dominated three-phase flow in porous media, Transport in Porous Media, 24, 167-201, 1996.

[9] Blunt, M.J., Jackson, M.D., Piri, M., Valvatne, P.H., Detailed physics, predictive capabilities and macroscopic consequences for pore-network models of multiphase flow, Advances in Water Resources, 25, 1069-1089, 2002.

[10] Piri, M., Blunt, M.J., Three-dimensional mixed-wet random pore-scale network modeling of two- and three-phase flow in porous media, I. Model description, Physical Review E, 71, 026301, 2005.

[11] Keller, A.A., Blunt, M.J., Roverts, P.V., Micromodel observation of the role of oil layers in three-phase flow, Transport in Porous Media, 26, 277-297, 1997.

[12] Fenwick, D.H., Blunt, M.J., Three-dimensional modeling of three phase imbibition and drainage, Advances in Water Resources, 21, 121-143, 1998. 